\title{
Learning research methods in art and design
}

\begin{abstract}
The purpose of this review is to represent the significance of learning the research methods in art and design, specifically. The review particularly focuses on learning the methods provided by two key researchers in art and design fields. In the book titled "visualize research: a guide to the research process in art and design", the authors take the reader into a journey with the powerful perception of visual thinking through the experimental approach used in this research category. The review also represents the authors' emphasis on learning research methods to conduct high-quality research studies in art and design, which ultimately impacts the world.
\end{abstract}

Volume 7 Issue 4 - 202I

\section{Sahar Ejeimi}

Fashion and Textiles, King Abdul Aziz University, Saudi Arabia

Correspondence: Sahar Ejeimi, King Abdul Aziz University, Jeddah, Saudi Arabia, Email sejeimi@kau.edu.sa

Received: June 20, 2021 | Published: July 02, 2021

Keywords: research, methods, design, quality, experimental

\section{Introduction}

Doing research in art and design has a crucial impact on developing related industry sectors. The field of art and design used to confused whether the inquiry in this field was considered research or as a practice to prove its contribution to knowledge. This confusion has been clarified and approved through the years. Thus, there has been a consideration for experimental research to be counted as empirical studies. However, many practitioners find it challenging to apply the research process to research in their art and design practice. The data is different, and the analysis in art and design differs from other fields; thus, many practitioners have their work limited to poster and gallery presentations. Consequently, this relatively limits the contribution of the empirical research in art and design to this field's knowledge.

Gray and Malins developed six chapters through a strategy for guidelines of the research process in art and design. The authors discuss the various methodologies required for conducting empirical research that practitioners would use in the book titled "Visualizing Research: A guide to the research process in art and design". The six sections of the book serve as a reference for the following:

a. Planning and preparation for research

b. Surveying the research context

c. Locating your research questions in relation to the context

d. Generating and gathering data through the use of research methods

e. Evaluating, analyzing, and interpreting your research outcomes

\section{f. Communicating your research findings}

Gray and Malins provide the reader with an overview of the research process methodologies in each aspect of the previous sections within the realm of art and design.

This book's primary goal is focused on the research methods that increase the quality of the artists and designers' practice to make an impact. The authors demonstrate new methodologies that place creative and design practices at the center of the research process. With their experience in the field of art and design, the authors provide a directly relevant reference for a practitioner with the visual analysis along with the standard provision in the field through the research process interaction with the design process, which fills the gap of lack of methodological guidance for students in art and design. Subsequently, this increases the research's impact that makes a difference to the world by the practitioner-researchers in the field.

In order to contribute to solving global problems, practitionerresearcher needs to understand the combination between practice and research that improves research quality in art and design. Practicing problem observation through practice raise questions that are the materials for research investigation. Investigation findings, in turn, impact the practice. Thus, Gray and Maline's innovative and creative research methods stand as an endeavor to meet the quality expected with the standard level of research for researchers in art and design. The authors provide the formal research with its rigorous and reflective approach in a creative approach that suits the experimental way in art and design with high quality.

Gray and Malin used the powerful means of metaphor to demonstrate the experimental approach creatively to facilitate knowledge through imaginative strategies. They intend to stress the significance of visual thinking in the learning process and try to help the reader visualize the exploration through the experimental research process using the metaphor "journey of exploration". This metaphor inspired from Alice in wonderland is in this book to take the reader into the exploration journey of the research process in art and design. ${ }^{1}$

\section{Acknowledgments}

None.

\section{Funding}

None.

\section{Conflicts of interest}

The authors have no conflict of interest regarding this paper.

\section{References}

1. Gray C, Malins J. Visualizing research: A guide to the research process in art and design. Routledge; 2016. 